Published in final edited form as:

Health Place. 2016 November ; 42: 129-136. doi:10.1016/j.healthplace.2016.09.012.

\title{
E-cigarette use among students and e-cigarette specialty retailer presence near schools
}

\author{
Georgiana Bostean, Ph.D. ${ }^{a}$, Catherine M. Crespi, Ph.D. ${ }^{b}$, Patsornkarn Vorapharuek, B.S. ${ }^{c}$, \\ and William J. McCarthy, Ph.D. ${ }^{d}$ \\ Georgiana Bostean: gbostean@chapman.edu; Catherine M. Crespi: ccrespi@ucla.edu; Patsornkarn Vorapharuek: \\ pvorapharuek@gmail.com; William J. McCarthy: wmccarth@ucla.edu \\ aDepartment of Sociology, Environmental Science \& Policy Program, Chapman University, One \\ University Drive, Orange, CA 92866, (714) 516-5910; fax: (714) 997-6823 \\ bepartment of Biostatistics, UCLA Fielding School of Public Health, 650 Charles E. Young Dr. \\ South, 51-254 CHS, Los Angeles, CA 90095-1772 \\ 'Environmental Management, University of San Francisco, Harney Science Center, 2130 Fulton \\ Street, San Francisco, CA 94117-1080 \\ dUCLA Fielding School of Public Health, Center for Cancer Prevention \& Control Research, \\ A2-125 CHS, 650 Charles Young Drive, Los Angeles 90095-6900; (310) 794-7587; fax: \\ 310-206-3566
}

\section{Abstract}

Objective-This study examined the association between presence of e-cigarette specialty retailers near schools and e-cigarette use among middle and high school students in Orange County (OC), CA.

Methods-The OC subsample of the 2013-2014 California Healthy Kids Survey ( $N=67,701)$ was combined with geocoded e-cigarette retailers to determine whether a retailer was present within one-quarter mile of each public school in OC. Multilevel logistic regression models evaluated individual-level and school-level e-cigarette use correlates among middle and high school students.

Results-Among middle school students, the presence of an e-cigarette retailer within onequarter mile of their school predicted lifetime e-cigarette use ( $O R=1.70,95 \% C I=1.02,2.83)$, controlling for confounders but no effect for current use. No significant effect was found for high school students.

Conclusions-E-cigarette specialty retailers clustered around schools may be an environmental influence on student e-cigarette experimentation.

\section{Keywords}

e-cigarette; substance use; retail environment; adolescence; Geographic Information Systems 


\section{Introduction}

Electronic cigarette (e-cigarette) use is increasing rapidly among U.S. adolescents, and is now more common among middle and high school students than conventional (combustible tobacco) cigarettes and other tobacco products (Arrazola et al., 2015; Singh et al., 2016b). Concurrently, there is increasing school-level clustering of e-cigarette use behaviors (Corsi and Lippert, 2016), suggesting that certain school environments facilitate e-cigarette use. One potential influence is the retail environment surrounding schools (Sanders-Jackson et al., 2015), which previous research has shown to be associated with other individual health behaviors, such as cigarette smoking or alcohol use (Braveman et al., 2011; West et al., 2010). Some studies have found that having more tobacco and alcohol retailers in proximity to schools and defined neighborhoods, whether proximity is defined by density or shortest distance to nearest retailer, is associated with use of those substances by students and neighborhood residents (Cederbaum et al., 2015; McCarthy et al., 2009; Young-Wolff et al., 2014). Yet no studies to date have examined whether the e-cigarette specialty retail environment is associated with e-cigarette use. Considering the increase in youth e-cigarette use (Arrazola et al., 2015), evaluating possible environmental factors influencing e-cigarette use among adolescents is an important area of research.

Despite on-going debates about the harms and benefits of e-cigarettes (Leventhal et al., 2015; Levy et al., 2016; Pisinger, 2014), use has been increasing among adolescents. In $2013,1 \%$ of middle school students and $4.5 \%$ of high school students nationally had used ecigarettes in the past 30 days; by 2015, the rates had more than tripled to $5.3 \%$ for middle and $16 \%$ for high school students (Singh et al., 2016b). Individual predictors associated with lifetime e-cigarette use (ever trying e-cigarettes) include being male, older, or a tobacco user (for review, see Carroll Chapman and Wu, 2014). Findings on racial/ethnic differences in adolescent use vary by geographic location and over time, with recent national studies finding inconsistent effects, including a study showing no difference between Hispanics and Whites in odds of ever using e-cigarettes but both exceeding the prevalence observed among non-Hispanic blacks (Singh et al., 2016b), a study in Connecticut finding higher rates of use among Whites (Krishnan-Sarin et al., 2015), and a study in California finding higher rates of use among Hispanics (Bostean et al., 2015). More research is needed to understand the socio-demographic, behavioral, and environmental correlates of e-cigarette use among adolescents in varying geographic locations across the U.S.

The retail environment is recognized as an important social determinant of health (Braveman et al., 2011; Marmot and Wilkinson, 1999; U.S. Department of Health and Human Services, 2015), influences various individual health behaviors (Hoek et al., 2010; Hsu et al., 2013; Story et al., 2008; Young-Wolff et al., 2014). According to ecological models (Sallis et al., 2008; Stokols, 1992; Wilcox, 2003), as part of the physical environment, retail environment may influence individual cognitions about health behaviors including knowledge, attitudes, preferences, and values (Story et al., 2008). Specifically, greater presence of retailers may influence adolescent health behaviors, including e-cigarette use, in several ways. First, retailer presence near schools increases visibility and awareness about the product, modeling and observation, perceived access (Lipperman-Kreda et al., 2016), and perceptions about substance use (Loomis et al., 2013; Milam et al., 2013), as recent studies have noted 
(Giovenco et al., 2016). Second, it may increase actual access to the product. For example, adolescents who know of a hookah (tobacco waterpipe) lounge in their community are more likely to have used hookah (Smith et al., 2011), and those with greater density of tobacco retailers near their home have greater intentions to smoke, and thereby greater likelihood of future smoking (Mennis et al., 2016). Third, presence of a specialty retailer near a school may increase students' exposure to promotional materials (e.g., product advertisements), which previous studies have found is correlated with higher odds of vaping (Agaku and AyoYusuf, 2014; Singh et al., 2016a), and causally linked with tobacco use (DiFranza et al., 2006), including smoking initiation (Henriksen et al., 2010), and with higher odds of adolescent alcohol consumption (Hurtz et al., 2007). Therefore, regardless of whether students are purchasing e-cigarettes from those particular retailers, the presence of retailers near schools may increase experimentation or use.

Empirical studies have found mixed support for the notion that retailer presence in proximity to schools can influence youth substance use, with effects varying based on the retail environment measure (retailer proximity or density), behavior (experimentation versus longer term use), and student grade level. For tobacco use, the proximity of tobacco retailers to an individuals' school or home is associated with tobacco use behaviors (Henriksen et al., 2008; Johns et al., 2013; Reitzel et al., 2011; West et al., 2010; Young-Wolff et al., 2014). Adolescents are more likely to experiment with or use tobacco when there are a greater number of tobacco retailers within walking distance of their homes or schools (LippermanKreda et al., 2012; McCarthy et al., 2009; Paynter and Edwards, 2009; West et al., 2010). A California study of tobacco retailers found higher lifetime cigarette smoking was associated with greater city-based tobacco outlet density (Lipperman-Kreda et al., 2016). Yet some previous studies found that retailer density was associated with tobacco lifetime use but not current smoking (Adams et al., 2013), or with experimentation but not with being an established smoker (McCarthy et al., 2009).

Moreover, the tobacco retail environment may differentially influence middle versus high school students, although the direction of the association is unclear. The transition from elementary to middle school is a period when adolescents are particularly prone to experimenting with substances (Eaton et al., 2012), therefore the tobacco retail environment may be particularly influential among younger adolescents, who are at an age when experimentation with substances including tobacco and alcohol increases sharply (Chen and Jacobson, 2012). A recent California longitudinal telephone survey study of youth found a greater effect of tobacco retailer density at earlier study waves, when respondents were 1316 years old (Lipperman-Kreda et al., 2016), and no effect at the third wave, when respondents were 15-18 years old, suggesting that retail environment may be more influential among younger students. Yet other studies found an effect of tobacco retailer presence only among high school students, but not middle school (McCarthy et al., 2009), and some studies examined only one of these school levels (Henriksen et al., 2008). Considering the processes driving the association between retail environment may differ for middle and high schools students, these groups should be examined separately.

This study aimed to extend existing literature by examining whether e-cigarette retailer presence near schools is associated with adolescent e-cigarette use, and whether the effect 
varies for middle school versus high school students. We examined data from Orange County (OC), an ethnically and socioeconomically diverse California county. One-third of OC students have tried e-cigarettes, which is twice as many as have tried conventional cigarettes (WestEd Health \& Human Development Program for the California Department of Education, 2013-2014). Prior to 2016, OC localities had few tobacco control regulations or e-cigarette regulations beyond the state law prohibiting the sale of e-cigarettes to minors (American Lung Association in California, 2014). E-cigarettes are sold by various retailers, such as liquor stores, convenience stores, and gas stations, and even on the internet, despite age restrictions (Williams et al., 2015). However, this study focused on e-cigarette specialty stores (also called "vape stores") because we were interested in the increasing visibility and number of $\mathrm{OC}$ e-cigarette retailers in the physical retail environment.

To examine our research question, we combined survey data on individual-level e-cigarette use among OC middle and high school students, with location data for all e-cigarettespecific retailers in OC. We used Geographic Information Systems (GIS) and multilevel regression to examine whether adolescents who attend schools with at least one e-cigarette retailer in close proximity to schools are more likely to use e-cigarettes than students in schools with no retailers nearby. Our approach permitted us to examine how school-level factors, particularly presence of retailers near the school, are related to individual behaviors, while accounting for clustering of individuals within schools (Raudenbush and Bryk, 2002). We examined retailer presence near schools rather than retailer density, common in the tobacco literature, because there are a relatively smaller number of e-cigarette specialty retailers than tobacco retailers. We also included individual level factors known to be associated with e-cigarette use (gender, race-ethnicity, cigarette smoking and other substance use), as well as parental education, and school-level socio-economic status. We stratified our sample by middle school versus high school to examine whether retailer presence has a differential effect, considering prior research suggesting different processes for these groups (Forza et al., 2012), consistent with federally-supported surveillance reporting practice (Johnston et al., 2004; Singh et al., 2016b) and following prior tobacco retail environment studies (Krishnan-Sarin et al., 2015; McCarthy et al., 2009). Based on previous literature, we hypothesized that presence of e-cigarette retailers in proximity to schools would be associated with higher odds of students ever using e-cigarettes, adjusting for individual sociodemographic and behavioral risk factors and school-level socio-economic status (SES). We expected this association to be stronger for middle school than for high school students based on previous research showing that younger students may be more influenced by the retail environment (Lipperman-Kreda et al., 2014), and because high school students' greater access to cars may make them less dependent on e-cigarette specialty retailers close to their school.

\section{Methods}

Data \& Sample

Student-level data came from the 2013-2014 California Healthy Kids Survey, the largest statewide school survey of risky behaviors in the US. The survey is conducted by WestEd, under contract to the California Department of Education (CDE). WestEd is a nonprofit 
educational research and development agency (Austin et al., 2013). The survey was designed to be administered at least once every two years to middle school and high school students, grades 7, 9 and 11, attending California public schools and to provide each district with a representative tobacco use profile of its students. School staff administered the survey using detailed instructions provided by WestEd. Participation was voluntary, anonymous, and confidential, and parental consent was obtained. For this study, all respondents attended OC public middle or high schools (including charter schools, excluding continuation and other non-traditional schools) in grades 7, 9, and 11. We excluded 2,621 respondents with missing data on key variables; this represented $3.7 \%$ of the sample, which is below the recommended $5 \%$ threshold for imputation (Tabachnick and Fidell, 2007). The final analytic sample consisted of 67,701 respondents in 130 schools.

For the school-level data, we compiled addresses for e-cigarette retailers in OC using a systematic internet search conducted during September 2014-March 2015 (as part of the Orange County E-cigarette Retailer Study). This online search methodology has been reported to be a valid and useful method by which to identify e-cigarette retailers in areas where there is no systematic licensure (Kim et al., 2016). Using search engines including Google, Yelp, and Yellowpages, three trained researchers conducted searches using the terms: "Orange County" and "electronic cigarettes," "e-cigarettes," or "vape." This search yielded 174 locations. We then limited results to retailers confirmed to be open for business during the survey period (September 2013 to June 2014); this information was ascertained by calling the retailer or through internet searches (e.g., examining the date of Yelp reviews documenting that the location is permanently closed, examining other websites with business license information). In all, we documented 148 e-cigarette-specific retailers in OC that were open during the survey period. A stratified random sample of 36 retailers were visited for ground truthing. Finally, we obtained addresses for all public middle and high schools (excluding continuation and non-traditional schools), and information about students' free/reduced price lunch program participation for each school, from the CDE (California Department of Education, 2016a, b).

\section{Dependent variables}

Lifetime e-cigarette use was defined as self-reported use of e-cigarettes one or more times in one's life. Current use was defined as self-reported use of e-cigarettes one or more times in the past 30 days.

\section{Key independent variable}

Because we examined e-cigarette specialty stores, the number of retailers in proximity to schools was small (range 0-2 for whole sample, but no middle schools had 2 nearby); thus we dichotomized the retailer density measure to indicate presence or absence of an e-cig specialty store proximal to a school. E-cigarette retailer presence was defined for each school as the presence of one or more e-cigarette-specific retailers within $1 / 4$ mile radius, which is often used in studies of retailer proximity for urban areas (Cederbaum et al., 2015; Simon et al., 2008; West et al., 2010); it is approximately the distance walked in 5 minutes, assuming a walking speed of 3.4 miles per hour. Students are more likely to walk to school if they live within this distance; a recent study found that $60 \%$ of children in the Los Angeles 
metropolitan area walk to school if they live less than 1/4 mile away (Sidharthan et al., 2011). We also conducted sensitivity analyses (results available upon request) with buffers at the half-mile and one-mile distance and results were non-significant, but in the same direction as found with the $1 / 4$-mile buffer.

To create this measure, the addresses of schools and e-cigarette retailers were geocoded using ArcMap 10.3 (ESRI, 2015). Buffer analysis was used to determine the number of ecigarette retailers located within one-quarter mile radius of each school. The buffer was defined using straight-line distance from the geocoded point, usually the school entrance. Sensitivity analyses examined a network buffer along roads, but found this approach excluded areas potentially accessible by foot because it did not account for the possibility of students exiting the school from points other than the front entrance; thus this approach yielded an undercount of accessible retailers.

\section{Covariates}

At the school-level, we controlled for Free/reduced price lunch program eligibility (FRLP) for the 2013-2014 academic year. This measure represents the percentage of K-12 students in a school who are eligible for the free or reduced price lunch program and is commonly used as a proxy for school-level SES (Pentz et al., 2015).

We controlled for the following individual-level measures: gender; race-ethnicity (nonHispanic White = reference; Hispanic; Black; Asian; Other); parent's education (less than college $=$ reference; college graduate; don't know/missing). To avoid excluding the $20 \%$ of students with missing information on parent's education, "missing/don't know" was included as a category. We also controlled for several self-reported behavioral risk factors: Tobacco ever use assessed whether the student had ever smoked conventional cigarettes or used smokeless tobacco (yes/no); Alcohol ever use indicated whether the respondent had ever had a full alcoholic drink (yes/no); Marijuana ever use indicated whether the respondent had ever tried marijuana (yes/no).

\section{Statistical Analyses}

Analyses were conducted using Stata version 13 (StataCorp LP, 2015). We summarized the individual-level characteristics, for the overall sample and separately for middle and high school students, and the school-level characteristics. Next, we compared the sociodemographic characteristics of e-cigarette users (lifetime and past 30 day use), testing for statistically significant differences using bivariate multilevel regressions for each variable. Lastly, we fit multivariable multilevel logistic regression models separately for middle school and high school students. These models estimated the odds ratios of ecigarette use controlling for individual- and school-level covariates. We accounted for clustering of responses within schools by including random intercepts for schools.

\section{Results}

Table 1 presents the sample characteristics. Among middle school ( $7^{\text {th }}$ grade) students, rates of e-cigarette use were $13.4 \%$ for lifetime use and $7.6 \%$ for current use. In terms of behavioral risk factors, alcohol use was the most common, with $12 \%$ of middle school 
students having ever drunk alcohol, compared to $6.8 \%$ who had ever used marijuana and $5.2 \%$ who had ever used tobacco. The sample had slightly more females $(51 \%)$ than males $(49 \%)$, more Hispanic origin (47.6\%) than White $(17.4 \%)$ or Asian (17.9\%); 39.4\% reported parental education as being college or higher. In terms of school-level characteristics, $3.9 \%$ of middle schools had at least one specialty e-cigarette retailer within $1 / 4$ mile, and the average school-level percent of students eligible for FRLP was 52.6\% in middle schools.

Among high school ( $9^{\text {th }}$ and $11^{\text {th }}$ grade) students, e-cigarette use rates were $27.5 \%$ and $13.7 \%$ for lifetime and current use, respectively. Rates of other behavioral risk factors were higher compared to middle school students, with $36.9 \%$ of high school students having ever had one full alcoholic drink, $24.8 \%$ having used marijuana, and $15.2 \%$ having ever used combustible tobacco. Socio-demographic characteristics were similar to middle school students, with slightly more females than males (51.4\%), a substantial proportion of Hispanic students (46\%), and approximately $45.1 \%$ reporting parental education of college or higher. In terms of school-level characteristics, $9.4 \%$ of high schools had at least one specialty e-cigarette retailer within $1 / 4$ mile, and the average school-level percent of students eligible for FRLP was $47.6 \%$.

Table 2 presents the prevalence of lifetime and current e-cigarette use by school-level and individual-level factors. Among middle school students, those who attended schools with at least one e-cigarette retailer near the school had approximately twice the rate of e-cigarette use, with statistically significant higher prevalence of both lifetime and current e-cigarette use. For lifetime use, $27.5 \%$ of middle school students attending schools with a retailer nearby had ever tried e-cigarettes, compared to $12.5 \%$ of students attending schools with no retailer present. For current use, the rates were $14.5 \%$ for those with a retailer present, versus $7.2 \%$ for those with no retailer present. E-cigarette use prevalence, both lifetime and current, also varied by socio-demographic characteristics and behavioral risk factors, with greater use among Hispanic students, those who report lower parent educational attainment, and those who have used other substances.

Among high school students, the difference in prevalence by retailer presence was not statistically significant $-31 \%$ versus $27.1 \%$ for lifetime use and $14.4 \%$ vs. $13.7 \%$ for current use. In contrast to middle school students, among high school students males had significantly higher rates of use than females $(15.1 \%$ vs. $12.5 \%)$. Similar to middle school students, e-cigarette users were generally more likely to be Hispanic, with parental education less than college, and had higher rates of combustible tobacco, alcohol, and marijuana use than non-users.

Table 3 addresses our main research question with multilevel logistic regression models predicting lifetime e-cigarette use for middle school and high school students, controlling for individual and school-level factors. The presence of a retailer near schools was associated with higher odds of lifetime e-cigarette use $(O R=1.70, C I=1.02,2.83)$ among middle school students, net of individual-level predictors of e-cigarette use, as well as school-level SES. In addition, odds of e-cigarette use were higher among students attending schools with a greater percentage of students eligible for FRLP $(O R=2.94, C I=2.04,4.26)$. All hypothesized individual-level correlates of lifetime e-cigarette use were significant. Females 
had lower odds of lifetime use than males $(O R=.84, C I=.76, .93)$. Compared with their White peers, Asians had lower odds, and Hispanic and Other race students had higher odds of lifetime e-cigarette use. Students whose parents had less than a college education had higher odds of lifetime use ( $O R=1.44, C I=1.24,1.66)$. The largest associations with ecigarette use were for other behavioral risk factors. Tobacco users had nearly 7 times higher odds of having ever used e-cigarettes, marijuana users 8 times, and alcohol users nearly 6 times the odds compared to their peers who had never used the respective substance. Overall, these findings support our main study hypothesis among middle school students for lifetime e-cigarette use, net of individual and school-level correlates of use.

By contrast, for high school students, neither retailer presence nor school-level FRLP eligibility were significantly associated with lifetime e-cigarette use. Socio-demographic patterns of e-cigarette use were similar to middle school students, with the exception of fewer racial/ethnic differences-only Asians differed significantly from Whites in their odds of use ( $O R=.69, C I=.62, .77)$. The behavioral risk factors were also strong predictors of use among high school students, with approximately 5 times greater odds of use among users of each substance. Finally, the intraclass correlation for both the middle and high school models revealed that, conditional on the fixed-effects covariates, there is significant unexplained clustering of lifetime e-cigarette use within schools.

Table 4 examined current e-cigarette use. Retailer presence was not a significant predictor of current use for either middle or high school. As for lifetime use, there was higher current use among middle school students who attended schools with a greater percentage of students eligible for FRLP $(O R=2.33, C I=1.53,3.54)$. For individual predictors of use, patterns were largely consistent with those for lifetime use, except that boys and girls had similar rates of current use.

Among high school students, as for middle school, retailer presence was not a significant predictor of current e-cigarette use. In contrast to middle schools, a higher percent of students eligible for FRLP was associated with lower odds of use ( $O R=0.65, C I=0.48$, 0.88 ) in high schools. Females had significantly lower odds of current use than males, Asians had lower odds of use than Whites, and those whose parents have lower education had higher odds of use. Behavioral risk factors all were significantly associated with higher odds of current use. As with lifetime use, there was significant unexplained clustering of current e-cigarette use within middle and high schools after accounting for variation explained by the fixed effects.

Sensitivity analyses were conducted to further examine current use, and whether greater distance from schools also predicted use. We examined past 30 day use of e-cigarettes on the subset of students who reported ever use, but these conditional results were unreliable due to the low exposure and current use; the effect of retailer presence remained non-significant. We also buffers at the half-mile and one-mile distance and results were non-significant, but in the same direction (see Table 2 in (Bostean et al., Submitted)). 


\section{Discussion}

This study documents how the retail environment—specifically, e-cigarette specialty retailer presence near schools-is associated with student e-cigarette use, beyond variance explained by individual and other school-level risk and protective factors. Overall, results reveal both individual and school-level factors to be associated with e-cigarette use among adolescents, and that predictors of e-cigarette use vary for middle versus high school students. Results provide some support for the hypothesis that presence of an e-cigarette retailer near school is associated with ever trying e-cigarettes among middle school students. Although the effects of individual sociodemographic characteristics on e-cigarette use are stronger, retailer presence is associated with greater odds of use of e-cigarettes even when controlling for combustible tobacco and other substance use. Several results have particularly important public health implications.

Our main finding is that presence of a specialty e-cigarette retailer near a middle school is associated with increased likelihood of lifetime e-cigarette use among its students. The fact that we controlled for several individual-level correlates of use including other substance use and parents' education, as well as school-level socio-economic status, bolsters confidence in this result. This finding is particularly noteworthy considering we focused on e-cigarette specialty retailers. Despite the fact that e-cigarettes can be purchased online and from other retailers, such as gas stations, we found a positive association of vape store presence with lifetime e-cigarette use. A plausible explanation for this association, based on tobacco retailer studies (Loomis et al., 2013), is that these specialty retailers increase visibility in addition to increasing access, potentially increasing awareness of and favorable perceptions about e-cigarette use. Future research can explore additional factors contributing to withinschool clustering of e-cigarette use behaviors (Corsi and Lippert, 2016), such as, for example, perceptions about e-cigarette norms and harms.

The non-significant findings for current e-cigarette use and for high school students are consistent with some previous research. The fact that retailer presence was a significant predictor only of lifetime use of e-cigarettes by middle school students, but not current use, is consistent with previous tobacco studies (Adams et al., 2013; McCarthy et al., 2009). Previous studies found that tobacco retailer density was associated with experimentation (McCarthy et al., 2009), which is common around the time of the transition from middle to high school (Eaton et al., 2012). Moreover, the lack of association among high school students may also be related to experimentation. These results suggest that retailer presence may matter more for experimentation among younger students, which recent studies have found to be true for the combustible tobacco retail environment (Lipperman-Kreda et al., 2016). As others have pointed out, not all adolescents who experiment go on to become long term users, however, experimentation is a necessary step to longer term use (Pierce et al., 1998). As a possible entry point to use of combustible tobacco products (Leventhal et al., 2015), influential factors in e-cigarette experimentation need to be better understood if prevention is to be effective.

Another important finding is that our prevalence estimates of e-cigarette use are high compared to much of the literature. In our sample of OC students, $27.5 \%$ of high school 
students had ever tried e-cigarettes, compared to an estimated $13.4 \%$ nationally for approximately the same period (Arrazola et al., 2015). Our estimates are close to those from a study conducted in Hawaii in 2013 that reported $29 \%$ of high school students having ever tried an e-cigarette (Wills et al., 2015), which appears to be the highest reported to date. Our middle school ( $7^{\text {th }}$ grade) estimates of lifetime use $(13.4 \%)$ are also substantially higher than the national estimate of 3.9\% (Arrazola et al., 2015), and slightly higher than estimates from a southern California study of $7^{\text {th }}$ graders in two school districts that found $11 \%$ of students had ever tried e-cigarettes (Pentz et al., 2015). The higher rates of e-cigarette use reported here compared with studies from other states and national studies may be due to geographic/ regional differences in e-cigarette use or may be due to regional differences in retail environments, policy environment, or sample composition (Orange County has more nonWhite students than other regional studies).

Our findings also illuminate racial and ethnic differences in e-cigarette use among adolescents. In this study, Hispanic middle school students are more likely than their White counterparts to use e-cigarettes. These results are similar to those of the National Youth Tobacco Survey, which found that among high school students, the rates of current ecigarette use among White and Hispanic students are approximately the same, but that among middle school students, rates of current e-cigarette use are higher among Hispanic compared to White adolescents (Arrazola et al., 2015; Singh et al., 2016b). Controlling for sociodemographic and behavioral risk factors, Hispanic $7^{\text {th }}$ grade students were more likely than White students to use e-cigarettes. These findings stand in contrast to studies in other states finding higher rates of use among White adolescents (Krishnan-Sarin et al., 2015), highlighting the importance of regional environment and context for shaping health behaviors.

These findings should be interpreted in the context of several limitations. First, results are associational rather than causal, as they are for all cross-sectional studies. Future studies may explore the pathways linking retailer presence and e-cigarette use among middle school students, such as awareness about e-cigarettes, perceptions about social acceptability and safety, and whether students purchase e-cigarettes preferentially from local retailers. Second, the strength of our main finding is limited considering the low rates of exposure to retailers in this county-level study. Additionally, the data are for grades 7, 9, and 11, which does not allow us to assess more nuanced differences across the middle and high school years. Given the sample ethnic composition from a diverse California county, the results are not generalizable to all students nationally. We were unable to conduct this study beyond only one county due to the high cost of identifying e-cigarette retailers (compared to alcohol and tobacco retailers, which in theory can be identified exhaustively using state licenses). Future studies should extend the spatial study of retailer proximity to other contexts outside of southern California, and examine the effect of retailer presence on frequency of e-cigarette use in order to distinguish between experimenters and longer-term users. Despite these limitations, the study strengths include the use of recent survey data from a large, diverse sample, and being among the first studies to document how e-cigarette specialty retailer locations are associated with student use. 
This study provided preliminary evidence that the e-cigarette retail environment influences this health behavior in middle school students. As Smedley and Amaro (Smedley and Amaro, 2016) argue, research is needed to build a science base on how to effectively address the social determinants of health to improve population health through place-based interventions. Health promotion programs, such as Healthy People 2020 (U.S. Department of Health and Human Services, 2015), that aim to create environments that discourage unhealthy behaviors may consider the impact of the e-cigarette retail environment. In the case of e-cigarettes, the presence of a retailer is associated with use among middle school students, who are at a developmental stage associated with increased experimentation with substances; studies are needed to understand the effects of policy regulation on e-cigarette use among adolescents. One policy approach that may reduce youth e-cigarette uptake that has been used to protect students from tobacco use and alcohol use is to require that new ecigarette retailers be located a minimum distance from schools (Ashe et al., 2003; Wooten et al., 2013). Application of the precautionary principle suggests that e-cigarette retailer proximity should be considered as a potential environmental risk factor for this health behavior, one that is modifiable through restrictive zoning designed to reduce adolescent vulnerability to e-cigarette marketing.

\section{References}

Adams ML, Jason LA, Pokorny S, Hunt Y. Exploration of the Link between Tobacco Retailers in School Neighborhoods and Student Smoking. The Journal of school health. 2013; 83:112-118. [PubMed: 23331271]

Agaku IT, Ayo-Yusuf OA. The Effect of Exposure to Pro-Tobacco Advertising on Experimentation With Emerging Tobacco Products Among U.S. Adolescents. Health Education \& Behavior. 2014; 41:275-280. [PubMed: 24347143]

American Lung Association in California. State of Tobacco Control. 2014. http://www.lung.org/ourinitiatives/tobacco/reports-resources/sotc/

Arrazola, RA.; Singh, T.; Corey, CG.; Husten, CG.; Neff, LJ.; Apelberg, BJ.; Bunnell, RE.; Choiniere, CJ.; King, BA.; Cox, S.; McAfee, T.; Caraballo, RS. Morbidity and Mortality Weekly Report (MMWR). Centers for Disease Control and Prevention; Atlanta, GA: 2015. Tobacco Use among Middle and High School Students-- United States, 2011-2014; p. 381-385.

Ashe M, Jernigan D, Kline R, Galaz R. Land Use Planning and the Control of Alcohol, Tobacco, Firearms, and Fast Food Restaurants. American Journal of Public Health. 2003; 93:1404-1408. [PubMed: 12948952]

Austin, G.; Bates, S.; Duerr, M. Guidebook for the California Healthy Kids Survey. WestEd; San Francisco: 2013.

Bostean G, Crespi CM, Vorapharuek P, McCarthy WJ. E-cigarette specialty retailers: Data to assess the association between retail environment and student e-cigarette use. Data in Brief. Submitted.

Bostean G, Trinidad D, McCarthy WJ. Prevalence and correlates of e-cigarette use by tobacco use status: Evidence from a diverse sample of California students. American Journal of Public Health. 2015

Braveman P, Egerter S, Williams DR. The Social Determinants of Health: Coming of Age. Annual Review of Public Health. 2011; 32:381-398.

California Department of Education. California Public School Directory. 2016a. http:// www.cde.ca.gov/re/pn/rc/pubschdirbro.asp

California Department of Education. Student Poverty Free and Reduced Price Meal Data. 2016b. http://www.cde.ca.gov/ds/sd/sd/filessp.asp 
Carroll Chapman SL, Wu LT. E-cigarette prevalence and correlates of use among adolescents versus adults: A review and comparison. Journal of Psychiatric Research. 2014; 54:43-54. [PubMed: 24680203]

Cederbaum JA, Petering R, Katherine Hutchinson M, He AS, Wilson JP, Jemmott JB III, Sweet Jemmott L. Alcohol outlet density and related use in an urban Black population in Philadelphia public housing communities. Health \& Place. 2015; 31:31-38. [PubMed: 25463915]

Chen P, Jacobson KC. Developmental Trajectories of Substance Use From Early Adolescence to Young Adulthood: Gender and Racial/Ethnic Differences. Journal of Adolescent Health. 2012; 50:154-163. [PubMed: 22265111]

Corsi DJ, Lippert AM. An examination of the shift in school-level clustering of US adolescent electronic cigarette use and its multilevel correlates, 2011-2013. Health \& Place. 2016; 38:30-38. [PubMed: 26796326]

DiFranza JR, Wellman RJ, Sargent JD, Weitzman M, Hipple BJ, Winickoff JP. for the Tobacco Consortium C.f.C.H.R.o.t.A.A.o.P. Tobacco Promotion and the Initiation of Tobacco Use: Assessing the Evidence for Causality. Pediatrics. 2006; 117:e1237-e1248. [PubMed: 16740823]

Eaton DK, Kann L, Kinchen S, Shanklin S, Flint KH, Hawkins J, Harris WA, Lowry R, McManus T, Chyen D, Whittle L, Lim C, Wechsler H. Youth Risk Behavior Surveillance - United States, 2011. Surveillance Summaries. 2012; 61(SS04):1-162. http://www.cdc.gov/mmwr/preview/ mmwrhtml/ss6104a1.htm.

ESRI. ArcGIS 10.3. ESRI; 2015.

Forza G, Buja A, Tognazzo F, Vinelli A, Baldo V, Amadori A. Smoking in Early and MidAdolescence. Journal of Developmental \& Behavioral Pediatrics. 2012; 33:449-455. [PubMed: 22772818]

Giovenco DP, Duncan DT, Coups EJ, Lewis MJ, Delnevo CD. Census tract correlates of vape shop locations in New Jersey. Health \& Place. 2016; 40:123-128. [PubMed: 27261635]

Henriksen L, Feighery EC, Schleicher NC, Cowling DW, Kline RS, Fortmann SP. Is adolescent smoking related to the density and proximity of tobacco outlets and retail cigarette advertising near schools? Preventive Medicine. 2008; 47:210-214. [PubMed: 18544462]

Henriksen L, Schleicher NC, Feighery EC, Fortmann SP. A Longitudinal Study of Exposure to Retail Cigarette Advertising and Smoking Initiation. Pediatrics. 2010; 126:232-238. [PubMed: 20643725]

Hoek J, Gifford H, Pirikahu G, Thomson G, Edwards R. How do tobacco retail displays affect cessation attempts? Findings from a qualitative study. Tobacco Control. 2010; 19:334-337. [PubMed: 20671091]

Hsu R, Myers AE, Ribisl KM, Marteau TM. An observational study of retail availability and in-store marketing of e-cigarettes in London: potential to undermine recent tobacco control gains? BMJ Open. 2013:3.

Hurtz SQ, Henriksen L, Wang Y, Feighery EC, Fortmann SP. The relationship between exposure to alcohol advertising in stores, owning alcohol promotional items, and adolescent alcohol use. Alcohol and alcoholism (Oxford, Oxfordshire). 2007; 42:143-149.

Johns M, Sacks R, Rane M, Kansagra S. Exposure to Tobacco Retail Outlets and Smoking Initiation among New York City Adolescents. Journal of Urban Health. 2013; 90:1091-1101. [PubMed: 23700202]

Johnston LD, O'Malley PM, Terry-McElrath YM. Methods, locations, and ease of cigarette access for American youth, 1997-2002. Am J Prev Med. 2004; 27:267-276. [PubMed: 15488355]

Kim AE, Loomis B, Rhodes B, Eggers ME, Liedtke C, Porter L. Identifying e-cigarette vape stores: description of an online search methodology. Tobacco Control. 2016; 25:e19-e23. [PubMed: 26205913]

Krishnan-Sarin S, Morean ME, Camenga DR, Cavallo DA, Kong G. E-cigarette Use Among High School and Middle School Adolescents in Connecticut. Nicotine \& Tobacco Research. 2015; 17:810-818. [PubMed: 25385873]

Leventhal AM, Strong DR, Kirkpatrick MG, et al. Association of electronic cigarette use with initiation of combustible tobacco product smoking in early adolescence. JAMA. 2015; 314:700 707. [PubMed: 26284721] 
Levy DT, Cummings KM, Villanti AC, Niaura R, Abrams DB, Fong GT, Borland R. A framework for evaluating the public health impact of e-cigarettes and other vaporized nicotine products. Addiction. 2016

Lipperman-Kreda S, Grube JW, Friend KB. Local Tobacco Policy and Tobacco Outlet Density: Associations With Youth Smoking. Journal of Adolescent Health. 2012; 50:547-552. [PubMed: 22626479]

Lipperman-Kreda S, Grube JW, Friend KB, Mair C. Tobacco outlet density, retailer cigarette sales without ID checks and enforcement of underage tobacco laws: associations with youths' cigarette smoking and beliefs. Addiction. 2016; 111:525-532. [PubMed: 26430730]

Lipperman-Kreda S, Mair C, Grube J, Friend K, Jackson P, Watson D. Density and Proximity of Tobacco Outlets to Homes and Schools: Relations with Youth Cigarette Smoking. Prevention Science. 2014; 15:738-744. [PubMed: 24254336]

Loomis BR, Kim AE, Goetz JL, Juster HR. Density of tobacco retailers and its association with sociodemographic characteristics of communities across New York. Public Health. 2013; 127:333338. [PubMed: 23515009]

Marmot, M.; Wilkinson, RG. Social determinants of health. Oxford University Press; Oxford [etc.]: 1999.

McCarthy WJ, Mistry R, Lu Y, Patel M, Zheng H, Dietsch B. Density of Tobacco Retailers Near Schools: Effects on Tobacco Use Among Students. American Journal of Public Health. 2009; 99:2006-2013. [PubMed: 19820214]

Mennis J, Mason M, Way T, Zaharakis N. The role of tobacco outlet density in a smoking cessation intervention for urban youth. Health \& Place. 2016; 38:39-47. [PubMed: 26798960]

Milam AJ, Furr-Holden CD, Bradshaw CP, Webster DW, Cooley-Strickland MC, Leaf PJ. ALCOHOL ENVIRONMENT, PERCEIVED SAFETY, AND EXPOSURE TO ALCOHOL, TOBACCO, AND OTHER DRUGS IN EARLY ADOLESCENCE. Journal of Community Psychology. 2013; 41:867-883. [PubMed: 25125766]

Paynter J, Edwards R. The impact of tobacco promotion at the point of sale: A systematic review. Nicotine \& Tobacco Research. 2009; 11:25-35. [PubMed: 19246438]

Pentz MA, Shin H, Riggs N, Unger JB, Collison KL, Chou CP. Parent, peer, and executive function relationships to early adolescent e-cigarette use: A substance use pathway? Addictive Behaviors. 2015; 42:73-78. [PubMed: 25462657]

Pierce JP, Choi WS, Gilpin EA, Farkas AJ, Berry CC. Tobacco industry promotion of cigarettes and adolescent smoking. JAMA. 1998; 279:511-515. [PubMed: 9480360]

Pisinger C. Why public health people are more worried than excited over e-cigarettes. BMC Medicine. $2014 ; 12: 1-5$.

Raudenbush, SW.; Bryk, AS. Hierarchical Linear Models: Applications and Data Analysis Methods. 2. Sage; Thousand Oaks: 2002.

Reitzel LR, Cromley EK, Li Y, Cao Y, Dela Mater R, Mazas CA, Cofta-Woerpel L, Cinciripini PM, Wetter DW. The Effect of Tobacco Outlet Density and Proximity on Smoking Cessation. American Journal of Public Health. 2011; 101:315-320. [PubMed: 21164089]

Sallis, JF.; Owen, N.; Fisher, EB. Ecological Models. In: Glantz, K.; Rimer, B.; Viswanath, K., editors. Health Behavior and Health Education: Theory, Research, and Practice. 4. Jossey-Bass; San Francisco, CA: 2008. p. 465-482.

Sanders-Jackson A, Parikh NM, Schleicher NC, Fortmann SP, Henriksen L. Convenience store visits by US adolescents: Rationale for healthier retail environments. Health \& Place. 2015; 34:63-66. [PubMed: 25955537]

Sidharthan R, Bhat C, Pendyala R, Goulias K. Model for Children's School Travel Mode Choice. Transportation Research Record: Journal of the Transportation Research Board. 2011; 2213:7886.

Simon PA, Kwan D, Angelescu A, Shih M, Fielding JE. Proximity of fast food restaurants to schools: Do neighborhood income and type of school matter? Preventive Medicine. 2008; 47:284-288. [PubMed: 18448158] 
Singh T, Agaku IT, Arrazola RA, Marynak KL, Neff LJ, Rolle IT, King BA. Exposure to Advertisements and Electronic Cigarette Use Among US Middle and High School Students. Pediatrics. 2016a:137. [PubMed: 27543009]

Singh, T.; Arrazola, RA.; Corey, CG.; Husten, CG.; Neff, LJ.; Homa, DM.; King, BA. CDC. MMWR Morb Mortal Wkly Rep. 2016b. Tobacco Use Among Middle and High School Students — United States, 2011-2015; p. 361-367.

Smedley B, Amaro H. Advancing the Science and Practice of Place-Based Intervention. American Journal of Public Health. 2016; 106:197-197.

Smith JR, Novotny TE, Edland SD, Hofstetter CR, Lindsay SP, Al-Delaimy WK. Determinants of Hookah Use among High School Students. Nicotine \& Tobacco Research. 2011; 13:565-572. [PubMed: 21454909]

StataCorp LP. Stata 13. College Station, TX: 2015.

Stokols D. Establishing and maintaining healthy environments. Toward a social ecology of health promotion. American Psychologist. 1992; 47:6-22. [PubMed: 1539925]

Story M, Kaphingst KM, Robinson-O’Brien R, Glanz K. Creating Healthy Food and Eating Environments: Policy and Environmental Approaches. Annual Review of Public Health. 2008; 29:253-272.

Tabachnick, B.; Fidell, L. Using multivariate statistics. 5. Pearson/Allyn and Bacon; Boston, MA: 2007.

U.S. Department of Health and Human Services. Social Determinants of Health. Healthy People 2020 Topics \& Objectives 2015. 2015. http://www.healthypeople.gov/2020/topics-objectives/topic/ social-determinants-health

West JH, Blumberg EJ, Kelley NJ, Hill L, Sipan CL, Schmitz KE, Ryan S, Clapp JD, Hovell MF. Does Proximity to Retailers Influence Alcohol and Tobacco Use Among Latino Adolescents? Journal of Immigrant and Minority Health. 2010; 12:626-633. [PubMed: 19936923]

WestEd Health \& Human Development Program for the California Department of Education. California Healthy Kids Survey, 2013-2014: Main Report San Francisco. 2013-2014.

Wilcox P. An ecological approach to understanding youth smoking trajectories: problems and prospects. Addiction. 2003; 98(Suppl 1):57-77. [PubMed: 12752362]

Williams RS, Derrick J, Ribisl KM. Electronic cigarette sales to minors via the internet. JAMA Pediatrics. 2015; 169:e1563. [PubMed: 25730697]

Wills TA, Knight R, Williams RJ, Pagano I, Sargent JD. Risk Factors for Exclusive E-Cigarette Use and Dual E-Cigarette Use and Tobacco Use in Adolescents. Pediatrics. 2015; 135:e43-e51. [PubMed: 25511118]

Wooten H, McLaughlin I, Chen L, Fry C, Mongeon C, Graff S. Zoning and Licensing to Regulate the Retail Environment and Achieve Public Health Goals. DUKE FORUM FOR LAW \& SOCIAL CHANGE. 2013:5.

Young-Wolff KC, Henriksen L, Delucchi K, Prochaska JJ. Tobacco Retailer Proximity and Density and Nicotine Dependence Among Smokers With Serious Mental Illness. American Journal of Public Health. 2014; 104:1454-1463. [PubMed: 24922145] 


\section{Table 1}

Sample characteristics (\%) of students and schools: Orange County (OC), CA

Middle school students $(\mathrm{n}=\mathbf{2 3 , 0 9 1 )}$ High school students $(\mathrm{n}=\mathbf{4 4 , 6 1 0})$

\section{Student characteristics}

Ever used e-cigarette (lifetime use)

\begin{tabular}{|c|c|}
\hline 13.4 & 27.5 \\
\hline 7.6 & 13.7 \\
\hline 5.2 & 15.2 \\
\hline 12.0 & 36.9 \\
\hline 6.8 & 24.8 \\
\hline 49.0 & 48.6 \\
\hline 51.0 & 51.4 \\
\hline 17.4 & 23.2 \\
\hline 47.6 & 46 \\
\hline 1.3 & 1.4 \\
\hline 17.9 & 17.7 \\
\hline 15.7 & 11.6 \\
\hline 39.4 & 45.1 \\
\hline 29.4 & 40.3 \\
\hline 31.3 & 14.7 \\
\hline Middle schools (n=77) & High schools $(n=53)$ \\
\hline 3.9 & 9.4 \\
\hline 52.6 & 47.6 \\
\hline
\end{tabular}
program (FRLP)

Source: Authors' calculations using data from the 2013-2014 California Healthy Kids Survey \& OC E-cigarette Retailer Study.

Note: Middle school includes grade 7, high school includes grades 9 and 11. 


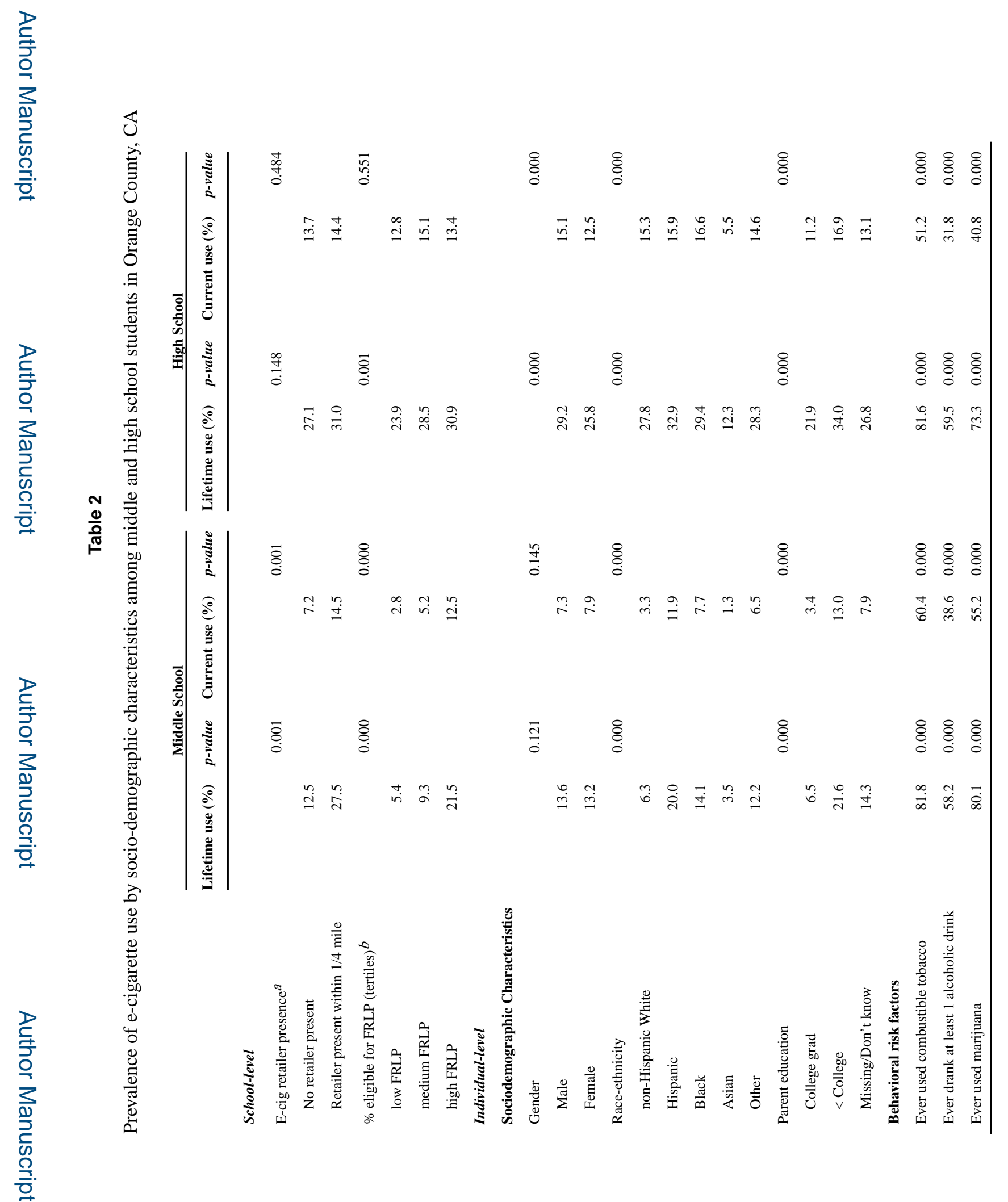

Health Place. Author manuscript; available in PMC 2017 November 01. 
Bostean et al.

Page 17

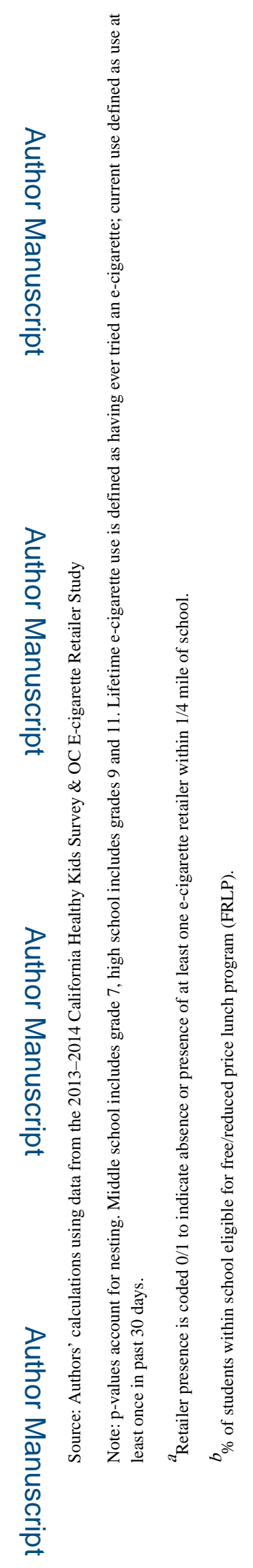

Health Place. Author manuscript; available in PMC 2017 November 01. 
Table 3

Lifetime e-cigarette use ${ }^{a}$ among students in Orange County, CA: Odds ratios from multilevel logistic regression models

Middle School (n=23,091) High School $(n=44,610)$

\begin{tabular}{llll}
\hline OR & $95 \% \mathrm{CI}$ & OR & $95 \% \mathrm{CI}$ \\
\hline
\end{tabular}

\section{School-level predictors}

\begin{tabular}{lllll} 
Retailer presence (ref=none within $1 / 4$ mile) ${ }^{b}$ & 1.70 & $(1.02-2.83)$ & 1.02 & $(0.81-1.29)$ \\
\% eligible for free/reduced lunch program ${ }^{c}$ & 2.94 & $(2.04-4.26)$ & 0.91 & $(0.71-1.17)$ \\
$\begin{array}{l}\text { Individual-level predictors } \\
\text { Sociodemographic characteristics }\end{array}$ & & & & \\
Female (ref=Male) & 0.84 & $(0.76-0.93)$ & 0.8 & $(0.75-0.85)$ \\
Race-ethnicity (ref=non-Hispanic White) & & & & \\
$\quad$ Hispanic & 1.54 & $(1.28-1.85)$ & 1.07 & $(0.98-1.16)$ \\
$\quad$ Black & 1.06 & $(0.65-1.74)$ & 0.84 & $(0.66-1.08)$ \\
$\quad$ Asian & 0.57 & $(0.44-0.74)$ & 0.69 & $(0.62-0.77)$ \\
$\quad$ Other & 1.31 & $(1.07-1.61)$ & 1.11 & $(1.00-1.22)$ \\
Parent education (ref=College grad) & & & & \\
$\quad$ < College graduate & 1.44 & $(1.24-1.66)$ & 1.26 & $(1.17-1.35)$ \\
$\quad$ Missing/Don't know & 1.23 & $(1.06-1.42)$ & 1.20 & $(1.09-1.31)$ \\
Behavioral risk factors & & & & \\
Tobacco ever use (ref=never used) & 6.84 & $(5.61-8.34)$ & 5.02 & $(4.63-5.43)$ \\
Alcohol ever use (ref= never had alcohol drink) & 5.83 & $(5.17-6.56)$ & 5.19 & $(4.87-5.53)$ \\
Marijuana ever use (ref= never used) & 8.15 & $(6.90-9.62)$ & 4.83 & $(4.52-5.15)$ \\
\hline Number of groups & 123 & & 83 & \\
Between-school variance (SE) & $.180(.041)$ & $.058(.015)$ \\
Intraclass correlation (SE) & $0.052(.011)$ & & $.017(.004)$ & \\
\hline
\end{tabular}

Source: Authors' calculations using California Healthy Kids Survey, 2013-2014 \& OC E-cigarette Retailer Study

Notes: Odds ratios derivd from multilevel logistic regressions (full model shown). Middle school includes grade 7, high school includes grades 9 and 11 .

Lifetime use is defined as having ever tried an e-cigarette.

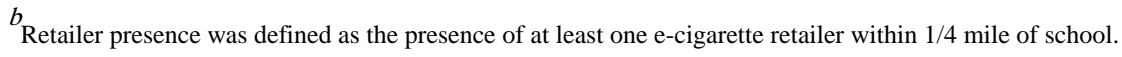

$c_{\%}$ of students within school eligible for free/reduced price lunch program (FRLP). 


\section{Table 4}

Current e-cigarette use ${ }^{a}$ among students in Orange County, CA: Odds ratios from multilevel logistic regression models

\begin{tabular}{|c|c|c|c|c|}
\hline & \multicolumn{2}{|c|}{ Middle School $(\mathrm{n}=\mathbf{2 3 , 0 9 1 )}$} & \multicolumn{2}{|c|}{ High School $(n=44,610)$} \\
\hline & OR & $95 \% \mathrm{CI}$ & OR & $95 \% \mathrm{CI}$ \\
\hline \multicolumn{5}{|l|}{ School-level predictors } \\
\hline Retailer presence $(\mathrm{ref}=$ none within $1 / 4$ mile) $b$ & 1.42 & $(0.82-2.46)$ & 0.96 & $(0.71-1.28)$ \\
\hline$\%$ eligible for free/reduced lunch program ${ }^{c}$ & 2.33 & $(1.53-3.54)$ & 0.65 & $(0.48-0.88)$ \\
\hline \multicolumn{5}{|l|}{ Individual-level predictors } \\
\hline \multicolumn{5}{|l|}{ Sociodemographic characteristics } \\
\hline Female (ref=Male) & 0.99 & $(0.88-1.12)$ & 0.84 & $(0.79-0.90)$ \\
\hline \multicolumn{5}{|l|}{ Race-ethnicity (ref=non-Hispanic White) } \\
\hline Hispanic & 1.57 & $(1.24-1.99)$ & 0.96 & $(0.87-1.05)$ \\
\hline Black & 0.85 & $(0.46-1.54)$ & 0.92 & $(0.70-1.20)$ \\
\hline Asian & 0.41 & $(0.29-0.60)$ & 0.68 & $(0.59-0.78)$ \\
\hline Other & 1.14 & $(0.87-1.48)$ & 1.04 & $(0.92-1.16)$ \\
\hline \multicolumn{5}{|l|}{ Parent education (ref=College grad) } \\
\hline$<$ College graduate & 1.36 & $(1.13-1.63)$ & 1.19 & $(1.10-1.29)$ \\
\hline Missing/Don’t know & 1.24 & $(1.03-1.50)$ & 1.18 & $(1.06-1.32)$ \\
\hline \multicolumn{5}{|l|}{ Behavioral risk factors } \\
\hline Tobacco use (ref=never used tobacco) & 4.79 & $(4.01-5.72)$ & 3.80 & $(3.53-4.09)$ \\
\hline Alcohol use (ref= no alcohol in past 30 days) & 5.04 & $(4.37-5.80)$ & 4.49 & $(4.10-4.92)$ \\
\hline Marijuana use (ref $=$ no use in past 30 days) & 4.53 & $(3.83-5.35)$ & 3.31 & $(3.05-3.59)$ \\
\hline Number of groups & \multicolumn{2}{|l|}{123} & \multicolumn{2}{|l|}{83} \\
\hline Between-school variance (SE) & \multicolumn{2}{|c|}{$.211(.049)$} & \multicolumn{2}{|c|}{$.096(.023)$} \\
\hline Intraclass correlation (SE) & \multicolumn{2}{|c|}{$.060(.013)$} & \multicolumn{2}{|c|}{$.028(.006)$} \\
\hline
\end{tabular}

Source: Authors' calculations using California Healthy Kids Survey, 2013-2014 \& OC E-cigarette Retailer Study

Notes: Odds ratios derivd from multilevel logistic regressions (full model shown). Middle school includes grade 7, high school includes grades 9 and 11 .

${ }^{a}$ Current use is defined as having used an e-cigarette in the past 30 days.

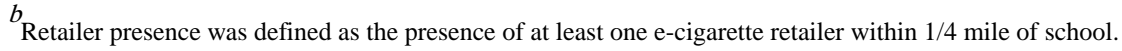

$c_{\%}$ of students within school eligible for free/reduced price lunch program (FRLP). 